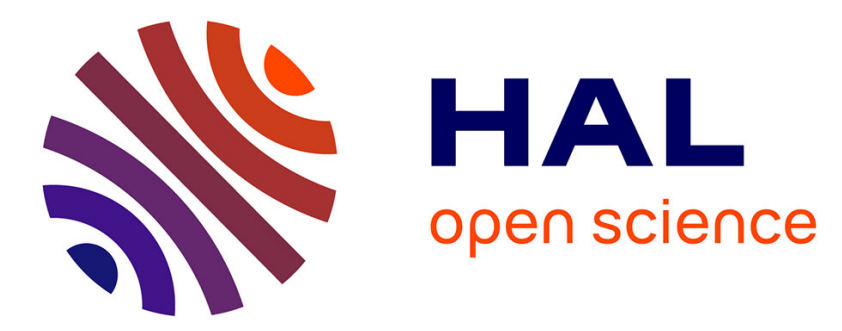

\title{
Magnetic and X-Ray Diffraction Studies on Dextran Iron-Oxide Magnetic Fluid
}

I. Sakamoto, H. Hasegawa, T. Hanaichi, I. Oguro, S. Maruno

\section{To cite this version:}

I. Sakamoto, H. Hasegawa, T. Hanaichi, I. Oguro, S. Maruno. Magnetic and X-Ray Diffraction Studies on Dextran Iron-Oxide Magnetic Fluid. Journal de Physique IV Proceedings, 1997, 07 (C1), pp.C1-561-C1-562. 10.1051/jp4:19971232 . jpa-00254906

\section{HAL Id: jpa-00254906 https://hal.science/jpa-00254906}

Submitted on 1 Jan 1997

HAL is a multi-disciplinary open access archive for the deposit and dissemination of scientific research documents, whether they are published or not. The documents may come from teaching and research institutions in France or abroad, or from public or private research centers.
L'archive ouverte pluridisciplinaire HAL, est destinée au dépôt et à la diffusion de documents scientifiques de niveau recherche, publiés ou non, émanant des établissements d'enseignement et de recherche français ou étrangers, des laboratoires publics ou privés. 


\title{
Magnetic and X-Ray Diffraction Studies on Dextran Iron-Oxide Magnetic Fluid
}

\author{
I. Sakamoto, H. Hasegawa, T. Hanaichi, I. Oguro* and S. Maruno
}

Nagoya Institute of Technology, Gokiso, Showa-ku, Nagoya 466, Japan

* The Institute for Solid State Physics, University of Tokyo, Minato-ku, Tokyo 106, Japan

\begin{abstract}
Two types of dextran iron-oxide complexes (ATDM and CMDM), magnetic fluid applicable to the contrast agent of magnetic resonance imaging of living body, have been synthesized without surfactant. We have measured temperature dependances of magnetization and X-ray diffraction of ATDM, CMDM and also magnetite fine-particles as a reference substance in atmospheres of air and helium up to $840^{\circ} \mathrm{C}$. The results are discussed in view of the reaction of magnetite core with the surrounding gas and products formed by thermal decomposition of the dextran molecules which is directly bonded to magnetite core of the complexes.
\end{abstract}

\section{INTRODUCTION}

Recentiy fine-particle iron-oxide magnetic complex has been paid much attention in numerous medical uses. For examples, they can act as a contrast agent in magnetic resonance imaging technology and localized heating agent by an RF generator in hyperthermia medical treatment. To apply the magnetic complex to living body, it is essential that the magnetic complex is non-toxic and is stabilized with biocompatible polymer. Two kinds of iron-oxide complexes with components of dextran, dextran derivatives and nanometer particles of $\mathrm{Fe}_{3} \mathrm{O}_{4}$ cores, which are expected to meet the above requirements, have been synthesized by the present authors[1-3]. One is the alkaline-treated dextran magnetite (ATDM) and the other is the carboxymethyl dextran magnetite (CMDM). In ATDM alkaline-treated dextran molecules which have the D-gluconic acid residue having $-\mathrm{COO}^{-} \mathrm{Na}^{+}$group at the terminal of dextran are linked to iron ion on magnetite core. On the other hand, in CMDM the magnetite core is linked with dextran derivatives in which the hydroxy group ( $-\mathrm{OR})$ on a D-glucitol terminal of the dextran reduced by sodium borohydride is replaced by $-\mathrm{OX} \mathrm{Na}^{+}$and some of hydroxy groups joined to the carbons 2,3 and 4 in D-glucopyranose are also replaced, where $\mathrm{X}=-\mathrm{CH}_{2} \mathrm{COO}$-, the carboxymethyl group. Because the alkaline-treated dextran and carboxymethyl dextran are bonded to the $\mathrm{Fe}_{3} \mathrm{O}_{4}$ cores through the carboxyl group $-\mathrm{COO}^{-}$, the core of $\mathrm{CMDM}$ is expected to be more firmly covered with the dextran derivative than that of ATDM with the dextran.

We have intended the systematic investigation of biological, medical, chemical and physical properties of these dextran magnetites to reveal an applicability of them to living body. We have reported the results on chemical, medical properties in previous papers[1-3]. In the present work we report the thermal stability of dextran magnetite in high temperatures in atmospheres of air and He by magnetization and $\mathrm{X}$-ray diffraction measurements.

\section{EXPERIMENTAL}

Alkaline-treated dextran and carboxymethyl dextran were prepared from dextran molecules with molecular weight of 4200 . ATDM and CMDM were synthesized in $\mathrm{pH}$ controlled aqueous solution of a mixture of ferrous chloride and ferric chloride and alkaline-treated dextran and carboxymethyl dextran, respectively, using Molday's method [4]. CMDM in which abont $20 \%$ of the $-\mathrm{OR}$ groups are replaced by $-\mathrm{OX} \mathrm{Na}^{+}$was used in the present work. The nanometer size dextran magnetite was selected by a successive use of filtration and centrifugation. X-ray diffraction patterers from ATDM and CMDM were measured by a standard powder diffractometry. The particle diameter was determined by Scherrer's equation using (311) plane to be 6-10 nm. Diffraction patters of ATDM and CMDM were found to agree with that of standard magnetite particles. Magnetization were measured by a vibrating samples magnetometer in atmospheres of air and $\mathrm{He}$. Temperature dependence curve at a field of $5 \mathrm{kG}$ was obtained in increasing temperature up to $850^{\circ} \mathrm{C}$ and in decreasing temperature down to room temperature. The rate of temperature change was $20^{\circ} \mathrm{C} / \mathrm{min}$.

\section{RESULTS AND DISCUSSION}

Figure 1 shows the temperature $(\mathrm{T})$ dependence of magnetization (M) of $\mathrm{Fe}_{3} \mathrm{O}_{4}$ particles(a), ATDM (b) and CMDM (c) measured in an atmosphere of He. Figure 1(a) shows that the two curves of $M$ for the $\mathrm{Fe}_{3} \mathrm{O}_{4}$ particles in increasing and decreasing temperatures agree and that the $\mathrm{Fe}_{3} \mathrm{O}_{4}$ particles are quite stable in the atmosphere of $\mathrm{He}$ up to a temperature as high as $800^{\circ} \mathrm{C}$. Figure $1(\mathrm{~b})$ shows that the magnetization of ATDM decreases initially, take maxima at $230^{\circ} \mathrm{C}$ and $370^{\circ} \mathrm{C}$ and reaches to zero at $580^{\circ} \mathrm{C}$ with increasing $\mathrm{T}$. As $\mathrm{T}$ increases further, the $\mathrm{M}$ curve shows a hump at about $700^{\circ} \mathrm{C}$ and again reaches to zero at $790^{\circ} \mathrm{C}$. When $\mathrm{T}$ decreases from $840^{\circ} \mathrm{C}$, the magnetization increases sharply at $790^{\circ} \mathrm{C}$ and tend to saturate below $600^{\circ} \mathrm{C}$. The value of $\mathrm{M}$ at room temperature is $1.9 \mu_{\mathrm{B}} / \mathrm{Fe}$, which nearly equals to that of bulk Fe. Figure $1(\mathrm{c})$ shows that the variation of $\mathrm{M}$ for $\mathrm{CMDM}$ in increasing $\mathrm{T}$ is similar to that of ATDM. But the different temperature dependence of $\mathrm{M}$ was 

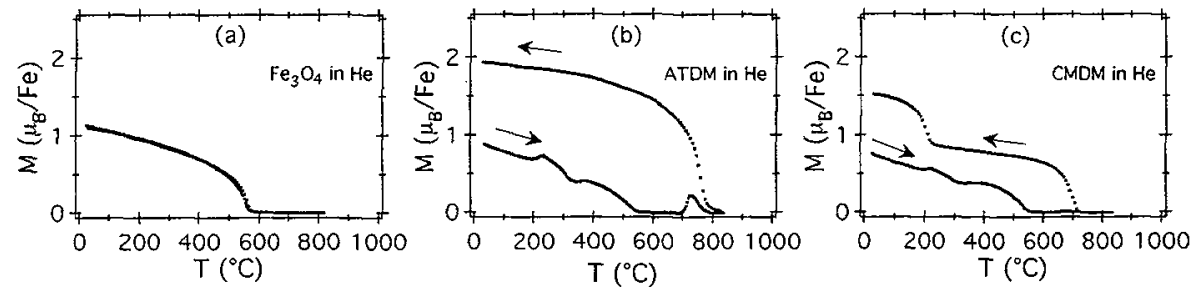

Figure 1 : Magnetizations of Fe304 particles(a), ATDM and CMDM in the atmosphere of He in increasing (the rightward arrow) and decreasing (the leftward arrow) temperatures.

observed in decreasing $\mathrm{T}$; first the $\mathrm{M}$ curve begin to increase at $720^{\circ} \mathrm{C}$ lower than that of $\mathrm{ATDM}$ by $70^{\circ} \mathrm{C}$ and second it again increases drastically at about $200^{\circ} \mathrm{C}$.

Dextran is known to dehydrate at about $200^{\circ} \mathrm{C}$ and to decompose into a mixture of carbohydrate, carbon oxide and carbon at $300^{\circ}-400^{\circ} \mathrm{C}$. If the dextran in DM is dehydrated and decomposed, then the state of Fe ions on the core surface of DM should be affected. Thus we can speculate that the first maximum at $\mathrm{T}=230^{\circ} \mathrm{C}$ in the $\mathrm{M}$ curve for ATDM is ascribed to the dehydration and the second maximum at $\mathrm{T}=370^{\circ} \mathrm{C}$ to the decomposition of the dextran. The hump at $\mathrm{T}=700^{\circ} \mathrm{C}$ indicate that the products formed by thermal decomposition of dextran begin to reduce the core state from $\mathrm{Fe}_{3} \mathrm{O}_{4}$ to $\alpha-\mathrm{Fe}$. Since the reduction is accelerated with increasing $T$, the concentration of $\alpha-F e$ in the core increases in higher temperatures. From this, we can understand that the $M$ curve in decreasing $\mathrm{T}$ agree practically with that of bulk Fe. As mentioned above, CMDM contains more carbon atoms in the neighborhood of the core than ATDM. Therefore carbon atoms in CMDM are used not only to reduce the $\mathrm{Fe}_{3} \mathrm{O}_{4}$ core, but also to react with the reduced $\alpha-\mathrm{Fe}$ core and to make a solid solution of $\mathrm{Fe}(\mathrm{C})$. The phase diagram of $\mathrm{Fe}-\mathrm{C}$ system shows that the eutectic reaction which divide the $\gamma-\mathrm{Fe}(\mathrm{C})$ phase into a mixture of the $\alpha-\mathrm{Fe}$ and $\mathrm{Fe}_{3} \mathrm{C}$ phases occurs at $\mathrm{T}=723^{\circ} \mathrm{C}$ and the carbon concentration of 0.08 at\%, where the $\gamma-\mathrm{Fe}(\mathrm{C})$ state is nonmagnetic while the $\mathrm{Fe}_{3} \mathrm{C}$ state the ferromagnet with the Curie temperature of $210^{\circ} \mathrm{C}$. The $\mathrm{M}$ curve above $720^{\circ} \mathrm{C}$ indicate that the core is in the $\gamma-\mathrm{Fe}(\mathrm{C})$ state. Thus when $\mathrm{T}$ reaches to $723^{\circ} \mathrm{C}$ from higher temperature, the phases of $\alpha-\mathrm{Fe}(\mathrm{C})$ and $\mathrm{Fe}_{3} \mathrm{C}$ are formed by the eutectic reaction. This is the reason why we observed the rapid increase of $\mathrm{M}$ at $720^{\circ} \mathrm{C}$ and also the drastic increase in $\mathrm{M}$ at about $200^{\circ} \mathrm{C}$. X-ray diffraction measurements of DM samples used for magnetization measurement supported our view clearly; the diffraction pattern for ATDM contain only the $\alpha-\mathrm{Fe}$ lines and those of $\mathrm{CMDM}$ a mixture of $\alpha-\mathrm{Fe}$ and $\mathrm{Fe}_{3} \mathrm{C}$ lines.
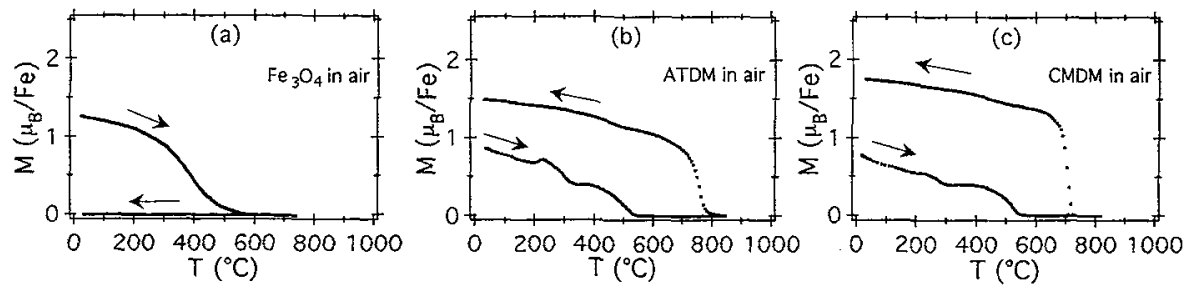

Figure 2: Magnetizations of Fe3O4 particles(a), ATDM and CMDM in the atmosphere of air in increasing (the rightward arrow) and decreasing (the leftward arrow) temperatures.

Figure 2 shows the temperature dependence of $\mathrm{M}$ for $\mathrm{Fe}_{3} \mathrm{O}_{4}$ particles(a), $\mathrm{ATDM}(\mathrm{b})$ and $\mathrm{CMDM}(\mathrm{c})$ in an atmosphere of air. Figures 2(a) shows that the $\mathrm{Fe}_{3} \mathrm{O}_{4}$ particle loses its magnetization on exposure to air at a temperature as high as $800^{\circ} \mathrm{C}$. This indicates that $\mathrm{Fe}_{3} \mathrm{O}_{4}$ particles are completely oxidized in air and changed to $\alpha-\mathrm{Fe}_{2} \mathrm{O}_{3}$ particles. Figure $2(\mathrm{~b})$ shows that the $\mathrm{M}$ curve in increasing $\mathrm{T}$ does not show a hump above $700^{\circ} \mathrm{C}$. This implies that the oxygen in the atmosphere prevents the $\mathrm{Fe}_{3} \mathrm{O}_{4}$ core from reducing by the products formed by thermal decomposition of dextran and that it preferably oxidizes these products instead. In fact, when we began to decrease $\mathrm{T}$ after arriving at $780^{\circ} \mathrm{C}$ in measuring $\mathrm{M}$ for ATDM in the atmosphere of air, we found that the $\mathrm{M}$ curve agrees qualitatively with that of $\mathrm{Fe}_{3} \mathrm{O}_{4}$ shown in Fig. 1(a). The $\mathrm{M}$ curve in decreasing $\mathrm{T}$ shown in Fig.2(b), which has similar temperture dependence to that of ATDM in the He atmosphere, indicates that $\mathrm{Fe}_{3} \mathrm{O}_{4}$ in the core are reduced to $\alpha-\mathrm{Fe}$ at temperatures as high as $800^{\circ} \mathrm{C}$. Figure 2(c) shows that the core state of $\mathrm{CMDM}$ is in the $\gamma-\mathrm{Fe}(\mathrm{C})$ state at the highest temperature and divided into the $\alpha-\mathrm{Fe}(\mathrm{C})$ and $\mathrm{Fe}_{3} \mathrm{C}$ states at the eutectic temperature of $723^{\circ} \mathrm{C}$. $\mathrm{This}^{\mathrm{Fe}} \mathrm{C}_{3} \mathrm{C}$ oxidized by the oxygen in the atmosphere of air with decreasing temperature from $723^{\circ} \mathrm{C}$. This is the reason why the $\mathrm{M}$ curve dose not have a abrupt increases at $200^{\circ} \mathrm{C}$.

\section{CONCLUSION}

we have found that the dextran and its derivative of DM prevent the core of DM from oxidizing in the environment where $\mathrm{Fe}_{3} \mathrm{O}_{4}$ particles is easily oxidized. This is the important point for application of DM to the contrast agent of magnetic resonance imaging for living body.

\section{References}

[1] Hasegawa M, Maruno S, Tobita M and Fujitsuka N, Adv. Biomater. 9(1990)517-522.

[2] Hasegawa M, Maruno S, Kawaguchi $\mathrm{K}$ and Moriya T, "Synthesis of dextran-magnetic iron oxide complex and its chemical and medical properties", Proc. of ICF6, Tokyo and Kyoto, Japan 1992, pp. 1007-1010.

[3] Moriya T, Hasegawa M, Kastuse H, Manuno S, Kawaguchi $\mathrm{K}$ and Kawaguchi $H$, "Mossbauer effects of dextran-magnetic iron oxide complexes", Proc. of ICF6, Tokyo and Kyoto, Japan 1992, pp. 1023-1026.

[4] Molday R.S. and Mackenzie D, J. Immunol. Methods. 52(1985)353-367. 